\title{
Impact of Fungiform Papillae Count on Taste Perception and Different Methods of Taste Assessment and their Clinical Applications A comprehensive review
}

"Asim M. Khan, ${ }^{1}$ Saqib Ali, ${ }^{1}$ Reshma V. Jameela, ${ }^{1}$ Muhaseena Muhamood, ${ }^{1}$ Maryam F. Haqh ${ }^{2}$

$$
\begin{aligned}
& \text { أثز عَدّ الحليمات الكميئة على إدراك حاسَّةُ الذَّوق والطرق }
\end{aligned}
$$

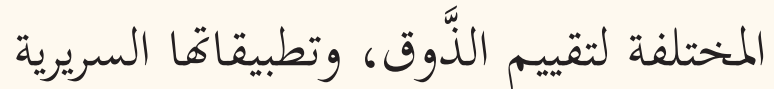

$$
\begin{aligned}
& \text { مراجعة شاملة }
\end{aligned}
$$

عاصم مصطفى خان، ثاقب علي، رشما جميلة، محاسنا محمود، مريم فسيحة حق

\begin{abstract}
Fungiform papillae are raised lingual structures which contain taste buds and thus play an important role in taste perception. These structures vary in number due to their relative sensitivity to a range of systemic and local factors which affect the dorsum of the tongue. Taste sensation can be measured using both chemical and electrical methods; however, the number of fungiform papillae has a direct effect on chemogustometric and electrogustometric values during evaluation. This review provides a general overview of fungiform papillae, their quantification methods and the various factors which may affect these structures. In addition, numerous methods of recording taste sensation and their clinical applications are highlighted.
\end{abstract}

Keywords: Sensation; Taste; Taste Perception; Tongue; Taste Buds; Investigative Techniques.

الملخص: الحليمات الكمئية هي بنيات لسينية مرتفعة تحتوي على براعم الذوق، ولهذا فهي تؤدي دورا ههما في إدراك حاسَّةُ الذَّ قوق. وتتفاوت

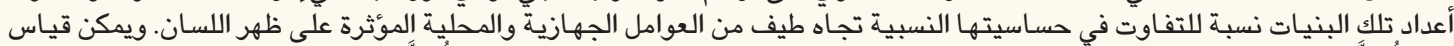

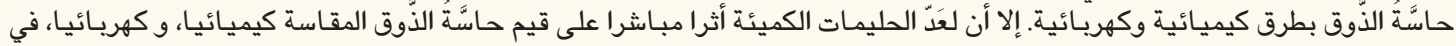

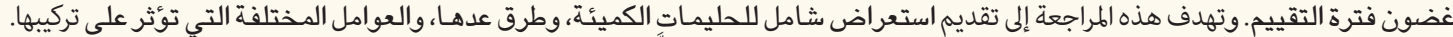

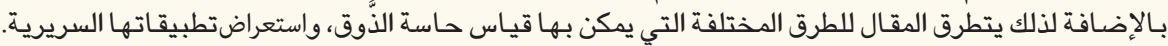

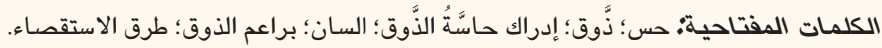

$\mathrm{F}$ UNGIFORM PAPILLAE ARE MUSHROOM-SHAPED structures located on the dorsum of the anterior two-thirds of the tongue. ${ }^{1-3}$ Due to their rich capillary network, larger size and patchy distribution, fungiform papillae can be identified as reddish dots that contrast to the smaller and more numerous filiform papillae. According to cadaveric data, each individual has an estimated 200 fungiform papillae which are denser on the tip of the tongue in comparison to the middle region (29 versus $7-8$ papillae per $\mathrm{cm}^{2}$ ). ${ }^{2,3}$ Each fungiform papilla carries between 0-20 taste buds, with an average of 2-4 buds; however, not all fungiform papillae contain taste buds and function as taste receptors at a given time. There are approximately 2,500 taste buds in the fungiform papillae of the anterior twothirds of the tongue, although this has been reported to vary by approximately 18 -fold between individuals. ${ }^{1-3}$
Based on their morphology, fungiform papillae are classified into four types that represent varying degrees of pathological severity. Type 1 fungiform papillae are the healthiest and are egg-shaped or long and elliptical and devoid of surface thickness, while type 2 are slightly thicker. Type 3 are thick and have an irregular surface while type 4-which represent the most pathological state-are flat and have an atrophic surface. ${ }^{4}$

Most studies investigating taste function utilise fungiform papillae count as a tool to indicate either decreased or increased taste sensitivity. ${ }^{5-7}$ To this end, fungiform papillae count has been correlated with various electrogustometric and chemogustometric thresholds. This review provides an overview of fungiform papillae, different methods for their quantification and the factors affecting these structures. In addition, various methods for recording taste sensation and their clinical applications are also discussed. 


\section{Taste Receptors}

The average human has a total of approximately 10,000 taste buds. ${ }^{8}$ These are located in the mucosa of the epiglottis, palate and pharynx as well as in fungiform and circumvallate papillae on the tongue. Fungiform papillae are most numerous around the tip of the tongue, whereas circumvallate papillae are arranged in a ' $\mathrm{V}$ ' pattern on the posterior third of the tongue immediately anterior to the sulcus terminalis. ${ }^{8}$ The taste buds on the fungiform papilla are mostly embedded on the surface of the papilla. In contrast, the larger circumvallate papillae have approximately 100 taste buds located in the side walls. ${ }^{8}$ The minute conical filiform papillae spread over the remaining tongue surface lack taste buds.

Taste buds are composed of ovoid bodies measuring $50-70 \mu \mathrm{m} .{ }^{8}$ Each bud consists of basal cells as well as type 1, 2 and 3 cells. Type 1 and 2 cells (i.e. sustentacular cells) support type 3 cells (i.e. the main gustatory cells) and are connected with sensory nerve fibres. ${ }^{8}$ Type 3 cells open up in the oral cavity via an opening called the taste pore which contain microvilli projecting from the taste cells. The necks of all three cell types are connected to each other and to the surrounding epithelial cells by tight junctions, so that only the microvilli are exposed to fluids in the oral cavity [Figure 1A]. ${ }^{9}$

Each taste bud is innervated by 50 nerve fibres which connect up to five taste buds each. ${ }^{8}$ The cells surrounding the taste buds give rise to basal cells which in turn differentiate into new taste receptor cells which replace the older ones every 10 days. ${ }^{8}$ Taste buds degenerate and finally disappear when the sensory nerve supplying them is severed. However, if the nerve regenerates, the surrounding cells become organised into new taste buds; this is attributed to the influence of a chemical inductive from the redeveloping nerve fibre. ${ }^{8}$

\section{Taste Pathway}

The chorda tympani is a branch of the facial nerve which innervates the taste buds on the anterior two-thirds of the tongue, while the posterior third of the tongue and taste buds situated in other areas (i.e. the palate and epiglottis) are innervated via the glossopharyngeal and vagus nerves, respectively. ${ }^{10}$ Taste sensation is carried to the gustatory area of the nucleus tractus solitarius in the medulla oblongata by slow-conducting myelinated nerve fibres. From the nucleus tractus solitarius, the neurons relay into the medial lemniscus of the medulla oblongata. $^{10}$

The axons of these second-order neurons then transmit directly to the ventral posteromedial nucleus of the thalamus where they travel via thalamic radiation to the anterior part of the ipsilateral insula which facilitates conscious perception of taste and taste discrimination [Figure 1B].$^{10}$ However, in some individuals, all or some of these second-order neurons may cross over to the contralateral side and synapse at the thalamus, projecting to the contralateral cerebral cortex, while the remaining fibres continue to project to the ipsilateral cerebral cortex, thus resulting in bilateral representation. ${ }^{11}$

\section{Taste Sensation}

Previously, it was believed that different areas of the tongue were responsible for perceiving the five different categories of taste (sweet, salty, bitter, sour and umami). ${ }^{12}$
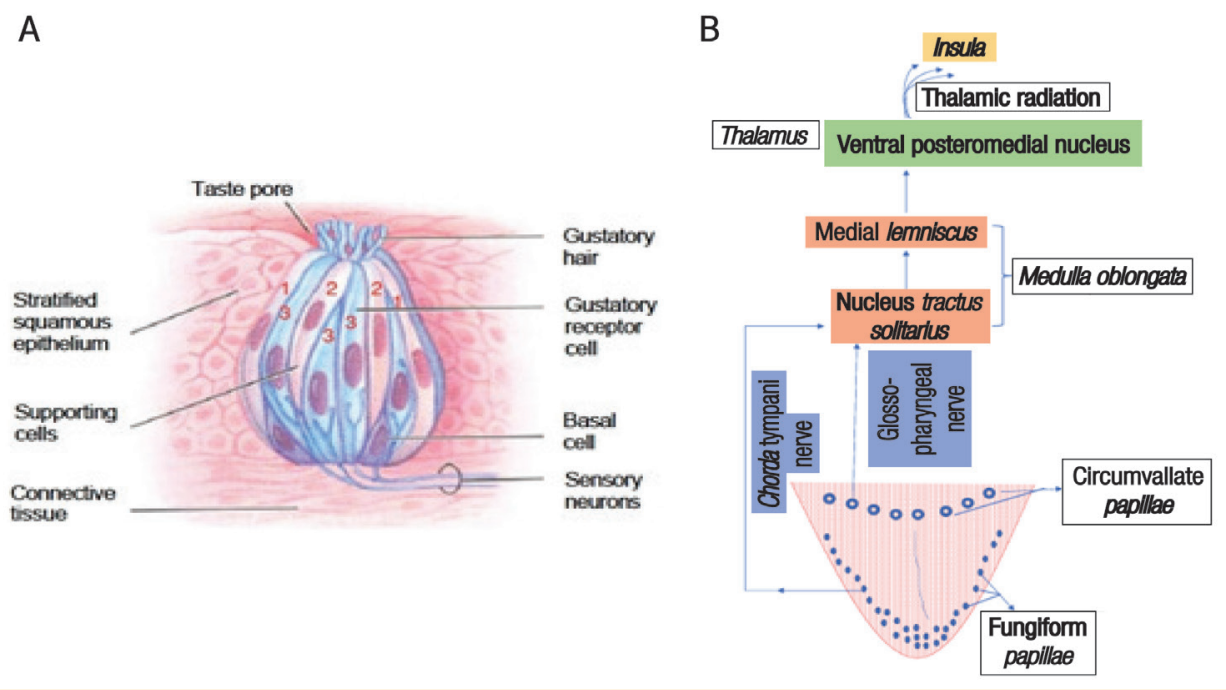

Figure 1: Annotated diagrams of (A) taste bud morphology and (B) the taste pathway.

Figure $1 \mathrm{~A}$ was modified and reproduced with permission from Gow thamarajan et al. ${ }^{9}$ 


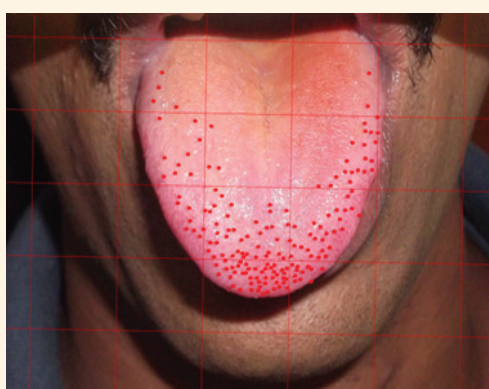

Figure 2: Image of fungiform papillae quantification using digital photography and computer software.

Reproduced with permission from Khan et al.?

However, it is now understood that the process of converting different taste stimuli into signals is not restricted to different zones of the tongue. Flavours are identified as a result of a backdrop of complex chemical mechanisms which involve ionic exchange through specific channels and secondary messenger activity. ${ }^{8,13}$ This process is known as taste signal transduction.

\section{SUPERTASTER PHENOMENON}

Supertaster phenomenon refers to the existence of individuals who experience tastes with far greater intensity than normal, to the degree that they can perceive usually tasteless substances, such as phenylthiocarbamide (PTC) and propylthiouracil (PROP). This concept was first described by Fox in 1932 when it was noted that PTC was tasteless to some individuals, yet perceived as bitter by others. ${ }^{14}$ While assessing the PTC taste response of over 2,500 subjects, Fox found that $65 \%$ of individuals recorded the taste as bitter, while $28 \%$ described it as tasteless and the remaining $6 \%$ described the taste in other ways. ${ }^{14}$

In recent years, research has revealed that this phenomenon is genetic in nature. ${ }^{13,15}$ This has been attributed to varying genotypes of the taste receptor 2 (TAS2R) member 38 gene. ${ }^{15-17}$ McMahon investigated supertaster phenomenon by assessing PROP taste status and papillae count among subjects who were able to appreciate unsweetened grapefruit juice; the results showed increased fungiform papillae density among supertasters, with non-supertasters having the lowest mean papillae densities. ${ }^{17}$ However, more recent research has shown that no correlation exists between fungiform papillae density and differences in taste perception. ${ }^{18,19}$

\section{Methods of Counting Fungiform Papillae}

\section{DIGITAL PHOTOGRAPHY}

Nasri-Heir et al. utilised digital photography to assess fungiform papillae count by using a camera with a resolution of at least five megapixels to photograph the tongue alongside a millimetre slide rule. ${ }^{6}$ Subsequently, using a computer, a grid was superimposed over the image and stretched to coincide with markings on the ruler in order to create $1 \mathrm{~cm}^{2}$-sized boxes. The papillae within these boxes were then counted and averaged to arrive at a mean value. ${ }^{6}$ This technique has also been supplemented with image analysis software [Figure 2]. ${ }^{7}$

\section{CONTACT ENDOSCOPY AND STAINING}

Pavlos et al. evaluated fungiform papillae density using contact endoscopy and the application of a methylene blue stain..$^{20}$ First, a contact technique without staining was performed to aid imaging of the subepithelial capillaries; subsequently, the stain was applied to the epithelia and taste pores using a $1 \mathrm{~cm}^{2}$-sized piece of filter paper placed around the tip of the tongue. The fungiform papillae were easily distinguishable as they were lightly stained in comparison to the darker filiform papillae. $^{20}$

\section{FOOD COLOURING DYE}

Zhang et al. used food dye (brilliant blue FCF133) to stain the tip of the tongue..$^{21}$ The dye was transferred to the tongue using a 6-mm circular piece of filter paper. The stained area was then photographed using a digital camera and the photographs subjected to analysis using Adobe Photoshop ${ }^{\circledR}$ software (Adobe Inc., San Jose, California, USA). ${ }^{21}$ An example of this technique is shown in Figure 3. ${ }^{19}$

\section{DENVER PAPILLAE PROTOCOL}

Nuessle et al. proposed a standardised method known as the Denver papillae protocol to define and prioritise the characteristics of fungiform papillae.22 This method involved manually counting the number of papillae in a 10-mm circular section of the tongue stained with a blue-coloured dye. Using image analysis software and digital photography, the fungiform papillae were then characterised based on their shape, colour, size and height. ${ }^{22}$ Individual fungiform papilla were rejected from the count if they were amorphous, stained blue in comparison to their surroundings, less than $0.5 \mathrm{~mm}$ in length or if they were lower in height compared to the surface of the tongue floor or the adjacent papillae. ${ }^{22}$

\section{AUTOMATED DETECTION}

Eldeghaidy et al. reported a method to automatically detect fungiform papillae on the dorsum of the tongue in collaboration with MATLAB $^{\circledR}$ image analysis software (MathWorks, Natick, Massachusetts, USA). ${ }^{18}$ The anterior $2 \mathrm{~cm}$ section of the dorsum of the tongue was automatically divided into eight regions by the software in which fungiform papillae were counted using various algorithms. However, one limitation of 

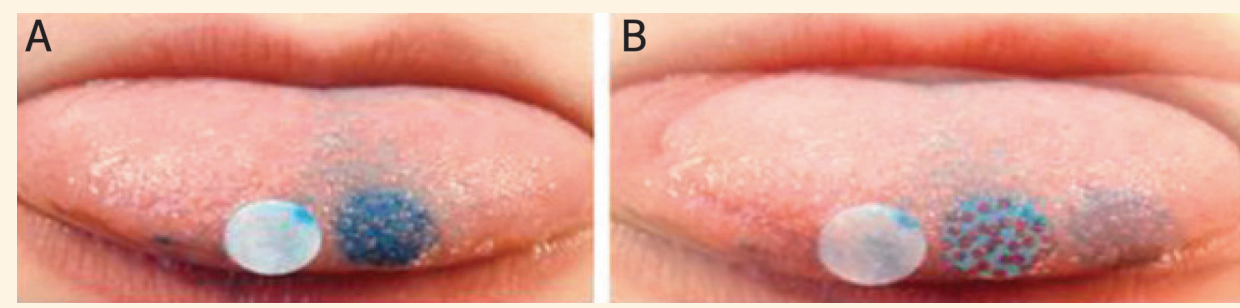

Figure 3: Photographs of tongue stained with brilliant blue FCF before (A) and after (B) fungiform papillae quantification. Reproduced with permission from Jilani et al. ${ }^{19}$

this methodology is that the software may inaccurately assess the diameter of the papillae because the software considers all fungiform papillae to be exactly circular in shape. ${ }^{18}$ Discrepancies have therefore been noted when the diameters of fungiform papillae are validated manually. ${ }^{18,23}$

\section{Factors Affecting Fungiform Papillae Count}

Nutrition and age are two major factors that affect the number of papillae present on the dorsum of the tongue. ${ }^{24,25}$ Certain nutrients such as vitamin B12 and folate are important to maintain an optimum balance between cell regeneration and deterioration; ${ }^{24}$ this is particularly important as the taste cells in the papillae have a high turnover rate. ${ }^{8}$ In addition, vitamin A deficiency may result in keratinisation and the loss of integrity of such cells in the epithelium. Zinc deficiency can also have similar consequences. ${ }^{24}$ Increasing age also slows down cellular regeneration, with $70 \%$ fewer taste buds recorded in individuals aged 70 years old compared to those aged 30 years. ${ }^{24}$ This also explains why many older individuals often have decreased taste sensitivity. ${ }^{25}$

Due to their high metabolic activity, cells forming filiform and fungiform papillae are also sensitive to enzyme, circulation or nutrient disturbances which can lead to atrophy. During atrophy, filiform papillae are more vulnerable to such disturbances compared to fungiform papillae; moreover, following atrophy, fungiform papillae regenerate faster in comparison to filiform papillae. ${ }^{24}$ Saito et al. reported that fungiform papillae atrophied among patients with normal preoperative gustatory function after sectioning of the chorda tympani nerve; subsequently, the papillae recovered after regeneration or re-adaption of the nerve. ${ }^{26}$ Spielman et al. biopsied fungiform papillae from the dorsum of the tongue and reported papillae regeneration at the same site after 40 days. ${ }^{27}$

Nasri-Heir et al. reported that the fungiform papillae count differed between patients with burning mouth syndrome and healthy controls $(27.554 \pm 2.122$ papillae per $\mathrm{cm}^{2}$ versus $31.575 \pm 3.112$ papillae per $\left.\mathrm{cm}^{2}\right)^{6}{ }^{6}$ Zhang et al. reported an inverse correlation between the number of fungiform papillae and taste thresholds using sucrose among young male subjects. ${ }^{21}$ Numerous other factors also affect the density of fungiform papillae, such as smoking. ${ }^{20}$ Various other potential causes of lingual papillae loss are listed in Table $1 .^{28}$

\section{Methods of Evaluating Taste Sensation}

The two primary methods of evaluating taste sensation are chemogustometry and electrogustometry.

Table 1: Factors potentially resulting in lingual papillae $\operatorname{loss}^{28}$

\begin{tabular}{|c|c|c|c|}
\hline Nutritional deficiencies & $\begin{array}{c}\text { Peripheral vascular } \\
\text { diseases }\end{array}$ & Local factors & Therapeutic agents \\
\hline $\begin{array}{l}\text { - Iron-deficiency anaemia } \\
\text { - Plummer-Vinson syndrome } \\
\text { • Pernicious anaemia } \\
\text { - Anaemia associated with } \\
\text { parasitic infections } \\
\text { (e.g. ascariasis and } \\
\text { bilharziasis) } \\
\text { - Tropical sprue or coeliac } \\
\text { disease } \\
\text { - Chronic alcoholism } \\
\text { - Vitamin B deficiency } \\
\text { (especially vitamin B2, B6, } \\
\text { B12, folic acid and nicotinic } \\
\text { acid) }\end{array}$ & $\begin{array}{l}\text { - Diabetic angiopathy } \\
\text { - Vasculitis in patients with } \\
\text { SLE } \\
\text { - Endarteritis obliterans } \\
\text { - Syphilitic glossitis } \\
\text { - Obliteration of the small } \\
\text { blood vessels (e.g. in } \\
\text { scleroderma or submucous } \\
\text { fibrosis) } \\
\text { - Localised vascular } \\
\text { insufficiency in elderly } \\
\text { patients }\end{array}$ & $\begin{array}{l}\text { - Frictional irritation to the } \\
\text { tip and lateral borders of the } \\
\text { tongue } \\
\text { - Atrophic lichen planus } \\
\text { - Epidermolysis bullosa or } \\
\text { ulceration which heals with } \\
\text { scarring } \\
\text { - Long-standing xerostomia }\end{array}$ & $\begin{array}{l}\text { - Drugs that interfere with the } \\
\text { growth and maturation of the } \\
\text { epithelium (e.g. cyclosporine) } \\
\text { • Drugs that induce } \\
\text { candidosis (e.g. antibiotics } \\
\text { and steroids) } \\
\text { - Drugs that induce } \\
\text { xerostomia } \\
\text { (e.g. anticholinergic drugs } \\
\text { and radiotherapy) }\end{array}$ \\
\hline
\end{tabular}




\section{CHEMOGUSTOMETRY}

Chemogustometry involves the application of chemical solutions to the oral mucosa; subsequently, the degree to which any of the five types of taste presents itself is evaluated by equating the taste with that of a reference material. ${ }^{29}$ Thus, taste detection thresholds are evaluated by asking the subject to taste a particular substance in various concentrations. This is done systematically by either increasing or decreasing the dilution of the substance. Water is used as a control during the process, with the subject ideally being able to discriminate between water and the diluted test solution. ${ }^{29}$ In order to appreciate any differences in the taste intensity of the substance being tested, there should be at least a $30 \%$ difference in dilution between solutions.

Bitterness is detected by the action of the bitter substance on TAS2R receptors, a type of G protein-linked receptor. ${ }^{16}$ Chemically, the threshold for bitterness is assessed using quinine hydrochloride at a dilution of $1 \mathrm{~g}$ in $2 \mathrm{~L}$ of water. ${ }^{23}$ Saltiness is evaluated by assessing the action of the salty substance on epithelial sodium channel $(\mathrm{ENaC})$ receptors using a diluted solution of sodium chloride. Taste transduction is thus induced by the influx of sodium ions in the $\mathrm{ENaC}$ receptors which facilitates the release of glutamate to depolarise neurons. Sourness, measured using diluted hydrochloric acid, also acts via the $\mathrm{ENaC}$ receptors which allow the inflow of protons and triggers neurons. .,23 $^{8}$

Sweetness is assessed using a diluted sweet substance such as sucrose or artificial sweeteners like saccharin, which differ in taste due to their distinct chemical structures. Taste transduction occurs via another $\mathrm{G}$ protein receptor known as taste receptor 1 . The final type of taste, umami, is savoury in nature. Umami taste is induced by the activation of metabotropic glutamate receptor 4 as a result of stimulants such as monosodium glutamate. Inosine monophosphate and guanosine monophosphate act as agonists during umami taste induction. . $^{83}$

\section{Taste strips and disks}

One method of chemogustometric evaluation involves presenting tastants to subjects in a clinical setting via soaked elongated strips or circular disks. ${ }^{30,31}$ These taste strips or disks are usually made up of pullulan ( $\alpha$-1,4- and $\alpha-1,6$-glucan) which is also combined with the polymer hydroxypropyl methylcellulose. Such strips or disks are dissolvable in the oral cavity and do not need to be retrieved afterwards. ${ }^{30}$

\section{The three-drop method}

Using this method, three drops of a chemical tasting solution are placed in the middle of the dorsum of the tongue, approximately $1.5 \mathrm{~cm}$ from the tip. ${ }^{31}$ One drop contains the actual tasting solution and the other two are distilled water drops which act as a solvent. The testing process usually starts with the lowest concentration, with the solution increasing in concentration until the subject's tasting threshold is detected. ${ }^{31}$

\section{Electroencephalography}

Event-related potentials refer to the electrical responses evoked in the brain when an individual is presented with a stimulus. As such, after applying chemical gustatory stimuli to the tongue, electroencephalography can show cortical brain activity associated with the taste sensation, along with its topographical distribution. ${ }^{32}$

\section{Advantages and disadvantages}

Chemogustometry consists of using an array of chemical solutions in multiple concentrations to assess taste sensation. Some advantages of this method include the long shelf-life of the materials needed, the ease of administration, the rapidity of testing and the fact that this method allows for evaluation of each side of the tongue separately. ${ }^{31}$ However, this method is qualitative in nature and more cumbersome in a clinical setting in comparison to electrogustometry.

\section{ELECTROGUSTOMETRY}

Electrogustometry quantifies taste and measures the threshold of taste sensation by passing a controlled current through the tongue using electrodes. As cathodal stimuli do not produce any significant recordable sensation, a weak anodal current is used. ${ }^{33}$ The stimulus is a constant direct current of predefined amplitude and duration. The taste perceived during electrogustometry is described as sour-metallic or 'battery'-like and is attributed to the absorption of protons (or hydronium ions) released by the stimulus. ${ }^{33}$

In 1754, Sulzer first described the 'ferro-sulphate'like metallic taste which occurs when two dissimilar metals come into contact with the tongue. ${ }^{34}$ In 1955 , Skouby invented the first electrogustometer based on taste thresholds determined by placing chemical solutions on the tongue. ${ }^{35}$ Subsequently, the measurement of taste using an electric stimulus was reported by Krarup in $1958 .{ }^{34}$ Over time, electrogustometers have evolved in terms of their design, electrode composition and size. ${ }^{33,35}$ Electrogustometry is now a viable clinical tool to estimate taste function, though this method is yet to be commonly used.

When an electrode from an electrogustometer is placed on tongue, two types of sensations are induced-tingling and taste..$^{33}$ These two sensations are conducted via different nerves, with taste perceived as a visceral sensation by the chorda tympani nerve while the tingling is a mechanical sensation conducted by the lingual nerve. Therefore, electrogustometry aids in differentiating between the chorda tympani and lingual 
nerves and is especially important in determining the integrity of the neural pathway. ${ }^{6,33}$ However, since electrogustometric taste threshold measurements are subjective, uniformity must be maintained in the environment/set-up of the test and the way the subject is trained to respond to the sensations.

\section{Advantages and disadvantages}

Electrogustometry is a quick and quantitative tool to assess taste threshold, particularly among patients with taste disorders such as hemiageusia and ageusia. ${ }^{32,36}$ Moreover, it allows for the evaluation of the most minute taste deficits, even in the absence of symptoms, and can be used to determine the topographical location of such deficits along the taste pathway and glossopharyngeal nerve. Furthermore, electrogustometry can also aid in determining patient prognosis. $^{36}$

However, a major drawback of electrogustometry is that it is subjective and relies on feedback from the subject. ${ }^{36}$ It also cannot be used to investigate or diagnose symptoms commonly associated with certain taste disorders, such as heterogeusia and spontaneous dysgeusia. Finally, this technique cannot be used for patients with artificial pacemakers as electrical stimuli from the electrodes may cause interference with electrical signals from the pacemaker. ${ }^{36}$

\section{Clinical Applications}

\section{BURNING MOUTH SYNDROME}

Braud et al. reported a significant association between electrogustometric values and pain intensity measured by visual analogue scale among patients with burning mouth syndrome, indicating a potent interaction between gustatory and nociceptive components among affected subjects. ${ }^{37}$ Nasri-Heir et al. also noted significantly higher electrogustometric responses among patients with burning mouth syndrome in comparison to a normal control group. ${ }^{6}$ The researchers concluded that burning mouth syndrome is a neurodegenerative phenomenon with decreased chorda tympani activity. ${ }^{6}$

\section{CANCER}

Ovesen et al. reported higher taste thresholds in subjects with small-cell lung, breast and ovarian cancer compared to controls with non-neoplastic disease. ${ }^{38}$ Moreover, taste thresholds decreased among those patients who responded to chemotherapy, suggesting that malignant disease has an effect on taste sensation. These findings indicate that electrogustometry could be a useful diagnostic tool in neoplastic cancers. ${ }^{38}$

Epstein et al. found that patients with cancer developed taste disorders (i.e. dysgeusia) as a result of other factors apart from pathology, such as chemotherapy treatment. ${ }^{39}$ This is because chemotherapy drugs are released into the saliva and adhere directly to the taste buds, causing altered taste perceptions and resulting in a metallic or chemical taste. As such, it is recommended that taste and olfactory electrogustometric evaluations be made mandatory for all patients undergoing cancer treatment. $^{39}$

\section{NEUROLOGICAL DISEASES}

Dzaman et al. reported that 13 out of 35 subjects with nasal polyps had increased taste and olfactory thresholds as assessed by electrogustometry compared to controls. ${ }^{40}$ Deeb et al. reported a deficit in electrogustometric thresholds among subjects with Parkinson's disease, indicative of disease severity. ${ }^{41}$

\section{POSTOPERATIVE PATIENTS}

Doty et al. assessed the impact of factors such as age and gender on taste perception among individuals undergoing chorda tympani nerve resection. ${ }^{42,43}$ Taste assessment was done in different regions of the tongue using filter paper soaked in tastants such as sucrose, sodium chloride and caffeine; in addition, the patients were subjected to electrical stimuli via electrogustometry. The researchers reported a deterioration in taste sensitivity commencing in middle age and progressively reducing after 50 years of age. ${ }^{42,43}$ This decline in taste sensitivity occurred for all stimuli at the anterior part of the tongue, with chorda tympani nerve resection resulting in taste deficits on the same side as well as the middle portion of the tongue. ${ }^{42,43}$

Boucher et al. investigated taste defects by electrogustometry in patients with severed afferent connections caused by dental treatment. ${ }^{44}$ Higher electrogustometric thresholds were recorded in subjects with more than seven deafferented teeth compared to those with fewer deafferented teeth, with a significant direct correlation between electrogustometric thresholds and the number of deafferented teeth, regardless of age. ${ }^{44}$ Similarly, Michael et al. found a greater prevalence of electrogustometric taste changes among patients following middle-ear surgery; this was ascribed to damage caused by the distention and, to a lesser degree, severance of the chorda tympani nerve. ${ }^{45}$

\section{SMOKING}

Depressed or altered taste sensation has been reported among chronic smokers. ${ }^{46,47}$ Smoke from burning tobacco includes a variety of irritants, oncogenic particles such as tar and lead, as well as other poisonous substances such as carbon monoxide and nicotine. These not only topically affect taste receptors cells and impede the normal mechanism of taste conduction 
but also affect the neurological transmission of taste sensations. ${ }^{46}$

The effects of tobacco on taste thresholds depend upon the individual's susceptibility, the quantity and frequency of use and the age of the individual when they started smoking. Using a modified form of electrogustometry, Khan et al. reported significantly lower fungiform papillae counts and greater electrical taste thresholds in smokers compared to non-smokers. ${ }^{7}$ Moreover, in a follow-up study of smokers before and after quitting, Chéruel et al. found that smoking cessation lead to a recovery in taste sensitivity. ${ }^{46}$ However, the time required to regain taste functionality depended on the susceptibility of the region of the tongue that had been affected. The researchers advocated for the use of electrogustometry as a method of motivating chronic smokers to stop smoking. ${ }^{46}$

Yekta et al. studied somatosensory function in the mucosa of the tongue. ${ }^{47}$ Subjects were tested bilaterally in tongue regions innervated by the lingual nerves according to sensory heat, pain and mechanical detection thresholds. Increased heat thresholds were reported in smokers in comparison to non-smokers; this was attributed to damage caused by smoking to the myelinated $\mathrm{A} \delta$ - and $\mathrm{C}$-fibres of the tongue. ${ }^{47}$

\section{Conclusion}

Fungiform papillae density offers valuable information regarding an individual's taste perception and taste sensation thresholds, with both chemical and electrical tools available for quantification purposes. However, as chemogustometry is a mostly qualitative method of determining taste sensitivity and requires a complex array of chemical solutions, it can be cumbersome in a clinical setting. In contrast, electrogustometry is a quick and quantitative tool and has a wide range of clinical applications, including for patients with taste disorders, burning mouth syndrome and neoplastic cancers as well as for smoking cessation purposes.

\section{References}

1. Miller IJ Jr, Bartoshuk LM. Taste perception, taste bud distribution, and spatial relationships. In: Getchell TV, Doty RL, Bartoshuk LM, Snow JB Jr, Eds. Smell and Taste in Health and Disease. New York, USA: Raven Press, 1991. Pp. 205-33.

2. Cheng LH, Robinson PP. The distribution of fungiform papillae and taste buds on the human tongue. Arch Oral Biol 1991; 36:583-9. https://doi.org/10.1016/0003-9969(91)90108-7.

3. Miller IJ Jr. Human fungiform taste bud density and distribution. Ann NY Acad Sci 1987; 510:501-3. https://doi. org/10.1111/j.1749-6632.1987.tb43604.x.
4. Negoro A, Umemoto M, Fukazawa K, Terada T, Sakagami M. Observation of tongue papillae by video microscopy and contact endoscopy to investigate their correlation with taste function. Auris Nasus Larynx 2004; 31:255-9. https://doi. org/10.1016/j.anl.2004.01.009.

5. Pavlidis P, Gouveris H, Kekes G. Electrogustometry thresholds, tongue tip vascularization, density, and form of the fungiform papillae following smoking cessation. Chem Senses 2017; 42:419-23. https://doi.org/10.1093/chemse/bjx009.

6. Nasri-Heir C, Gomes J, Heir GM, Ananthan S, Benoliel R, Teich S, et al. The role of sensory input of the chorda tympani nerve and the number of fungiform papillae in burning mouth syndrome. Oral Surg Oral Med Oral Pathol Oral Radiol Endod 2011; 112:65-72. https://doi.org/10.1016/j.tripleo.2011.02.035.

7. Khan AM, Narayanan VS, Puttabuddi JH, Chengappa R, Ambaldhage VK, Naik P, et al. Comparison of taste threshold in smokers and non-smokers using electrogustometry and fungiform papillae count: A case control study. J Clin Diagn Res 2016; 10:ZC101-5. https://doi.org/10.7860/JCDR/2016/14 478.7835 .

8. Barrett K, Brooks H, Boitano S, Barman S. Ganong's Review of Medical Physiology, 23rd ed. New York, USA: McGraw-Hill Medical, 2009

9. Gowthamarajan K, Kulkarni GT, Kumar MN. Pop the pills without bitterness: Taste-masking technologies for bitter drugs. Resonance 2004; 9:25-32. https://doi.org/10.1007/BF0 2834304.

10. Guyton AC, Hall JE. Textbook of Medical Physiology, 11th ed. Philadelphia, Pennsylvania, USA: Saunders Co., 2006.

11. Kamath MG, Prakash J, Tripathy A, Concessao P. Taste pathway: What do we teach? J Clin Diagn Res 2015; 9:CL01. https://doi.org/10.7860/JCDR/2015/11021.5471.

12. ScienceDaily. Biologists discover how we detect sour taste. From: www.sciencedaily.com/releases/2006/08/060823184824. htm Accessed: Mar 2019.

13. Bartoshuk LM. Comparing sensory experiences across individuals: Recent psychophysical advances illuminate genetic variation in taste perception. Chem Senses 2000; 25:447-60. https://doi.org/10.1093/chemse/25.4.447.

14. Fox AL. The Relationship between chemical constitution and taste. Proc Natl Acad Sci U S A 1932; 18:115-20. https://doi. org/10.1073/pnas.18.1.115.

15. Cannon DS, Baker TB, Piper ME, Scholand MB, Lawrence DL, Drayna DT, et al. Associations between phenylthiocarbamide gene polymorphisms and cigarette smoking. Nicotine Tob Res 2005; 7:853-8. https://doi.org/10.1080/14622200500330209.

16. Maehashi K, Matano M, Wang H, Vo LA, Yamamoto Y, Huang L. Bitter peptides activate hTAS2Rs, the human bitter receptors. Biochem Biophys Res Commun 2008; 365:851-5. https://doi. org/10.1016/j.bbrc.2007.11.070.

17. McMahon KA. Supertasters: Updating the taste test for the A \& P Laboratory. Poster from the Proceedings of the 29th Conference of the Association for Biology Laboratory Education. Test Stud Lab Teach 2008; 29:398-405.

18. Eldeghaidy S, Thomas D, Skinner M, Ford R, Giesbrecht T, Thomas A, et al. An automated method to detect and quantify fungiform papillae in the human tongue: Validation and relationship to phenotypical differences in taste perception. Physiol Behav 2018; 184:226-34. https://doi.org/10.1016/j.phy sbeh.2017.12.003.

19. Jilani H, Ahrens W, Buchecker K, Russo P, Hebestreit A; IDEFICS consortium. Association between the number of fungiform papillae on the tip of the tongue and sensory taste perception in children. Food Nutr Res 2017; 61:1348865. https://doi.org/10.1080/16546628.2017.1348865. 
20. Pavlos P, Vasilios N, Antonia A, Dimitrios K, Georgios K, Georgios A. Evaluation of young smokers and non-smokers with electrogustometry and contact endoscopy. BMC Ear Nose Throat Disord 2009; 9:9. https://doi.org/10.1186/1472-6815-9-9.

21. Zhang GH, Zhang HY, Wang XF, Zhan YH, Deng SP, Qin YM. The relationship between fungiform papillae density and detection threshold for sucrose in the young males. Chem Senses 2009; 34:93-9. https://doi.org/10.1093/chemse/bjn059.

22. Nuessle TM, Garneau NL, Sloan MM, Santorico SA. Denver papillae protocol for objective analysis of fungiform papillae. J Vis Exp 2015; 100:e52860. https://doi.org/10.3791/52860.

23. Piochi M, Dinnella C, Prescott J, Monteleone E. Associations between human fungiform papillae and responsiveness to oral stimuli: Effects of individual variability, population characteristics, and methods for papillae quantification. Chem Senses 2018; 43:313-27. https://doi.org/10.1093/chemse/bjy015.

24. Kamath SK. Taste acuity and aging. Am J Clin Nutr 1982 36:766-75. https://doi.org/10.1093/ajcn/36.4.766.

25. Arvidson K. Location and variation in number of taste buds in human fungiform papillae. Scand J Dent Res 1979; 87:435-42. https://doi.org/10.1111/j.1600-0722.1979.tb00705.x.

26. Saito T, Narita N, Yamada T, Manabe Y, Ito T. Morphology of human fungiform papillae after severing chorda tympan nerve. Ann Oto Rhinol Laryngol 2011; 120:300-6. https://doi. org/10.1177/000348941112000504.

27. Spielman AI, Pepino MY, Feldman R, Brand IG. Technique to collect fungiform (taste) papillae from human tongue. J Vis Exp 2010; 42:2201. https://doi.org/10.3791/2201.

28. Laskaris G. Pocket Atlas of Oral Diseases, 2nd ed. Stuttgart, Germany: Thieme, 2005

29. Simmen B, Pasquet P, Hladik CM. Methods for assessing taste abilities and hedonic responses in human and non-human primates. In: Macbeth H, MacClancy J, Eds. Researching Food Habits: Methods and problems. Oxford, UK: Berghahn Books, 2004. Pp. 87-99.

30. Doty RL. Measurement of chemosensory function. World J Otorhinolaryngol Head Neck Surg 2018; 4:11-28. https://doi. org/10.1016/j.wjorl.2018.03.001.

31. Mueller CA, Kallert S, Renner B, Stiassny K, Temmel AF, Hummel T, et al. Quantitative assessment of gustatory function in a clinical context using impregnated "taste strips". Rhinology 2003; 41:2-6.

32. Hummel T, Genow A, Landis BN. Clinical assessment of human gustatory function using event related potentials. J Neurol Neurosurg Psychiatry 2010; 81:459-64. https://doi. org/10.1136/jnnp.2009.183699.

33. Sardana DS, Mittal DP, Saha AK, Singh DP, Bassi NK. Electrogustometry: A physiological study. Indian J Otolaryngol 1975; 27:127-33.

34. Krarup B. Electro-gustometry: A method for clinical taste examinations. Acta Otolaryngol 1958; 49:294-305. https://doi. org/10.3109/00016485809134758.
35. Grant R, Ferguson MM, Strang R, Turner JW, Bone I. Evoked taste thresholds in a normal population and the application of electrogustometry to trigeminal nerve disease. J Neurol Neurosurg Psychiatry 1987; 50:12-21. https://doi.org/10.1136/ jnnp.50.1.12

36. Tomita H, Ikeda M. Clinical use of electrogustometry: Strengths and limitations. Acta Otolaryngol Suppl 2002; 122:27-38. https://doi.org/10.1080/00016480260046391.

37. Braud A, Descroix V, Ungeheuer MN, Rougeot C, Boucher Y. Taste function assessed by electrogustometry in burning mouth syndrome: A case-control study. Oral Dis 2017; 23:395-402. https://doi.org/10.1111/odi.12630

38. Ovesen L, Sørensen M, Hannibal J, Allingstrup L. Electrical taste detection thresholds and chemical smell detection thresholds in patients with cancer. Cancer 1991; 68:2260-5. https://doi.org/10.1 002/1097-0142(19911115)68:10<2260::AID-CNCR28206810 26>3.0.CO; $2-\mathrm{W}$

39. Epstein JB, Barasch A. Taste disorders in cancer patients: Pathogenesis, and approach to assessment and management. Oral Oncol 2010; 46:77-81. https://doi.org/10.1016/j.oralonco logy.2009.11.008

40. Dzaman K, Pleskacz WA, Wałkanis A, Rapiejko P, Jurkiewicz D. [Taste and smell senses estimation in patients with nasal polyps]. Otolaryngol Pol 2007; 61:831-7. https://doi.org/10.1016/S003 $0-6657(07) 70537-1$.

41. Deeb J, Shah M, Muhammed N, Gunasekera R, Gannon K, Findley LJ, et al. A basic smell test is as sensitive as a dopamine transporter scan: Comparison of olfaction, taste and DaTSCAN in the diagnosis of Parkinson's disease. QJM 2010; 103:941-52. https://doi.org/10.1093/qjmed/hcq142.

42. Doty RL, Heidt JM, MacGillivray MR, Dsouza M, Tracey EH, Mirza N, et al. Influences of age, tongue region, and chorda tympani nerve sectioning on signal detection measures of lingual taste sensitivity. Physiol Behav 2016; 155:202-7. https://doi.org/10.1 016/j.physbeh.2015.12.014

43. Doty RL. Age-related deficits in taste and smell. Otolaryngol Clin North Am 2018; 51:815-25. https://doi.org/10.1016/j.otc.2 018.03.014.

44. Boucher Y, Berteretche MV, Farhang F, Arvy MP, Azérad J, Faurion A. Taste deficits related to dental deafferentation: An electrogustometric study in humans. Eur J Oral Sci 2006; 114:456-64. https://doi.org/10.1111/j.1600-0722.2006.00401.x.

45. Michael P, Raut V. Chorda tympani injury: Operative findings and postoperative symptoms. Otolaryngol Head Neck Surg 2007; 136:978-81. https://doi.org/10.1016/j.otohns.2006.12.022.

46. Chéruel F, Jarlier M, Sancho-Garnier H. Effect of cigarette smoke on gustatory sensitivity, evaluation of the deficit and of the recovery time-course after smoking cessation. Tob Induc Dis 2017; 15:15. https://doi.org/10.1186/s12971-017-0120-4.

47. Yekta SS, Lückhoff A, Ristić D, Lampert F, Ellrich J. Impaired somatosensation in tongue mucosa of smokers. Clin Oral Investig 2012; 16:39-44. https://doi.org/10.1007/s00784-0100480-0. 